\title{
Conseils pour médecins et cabinets
}

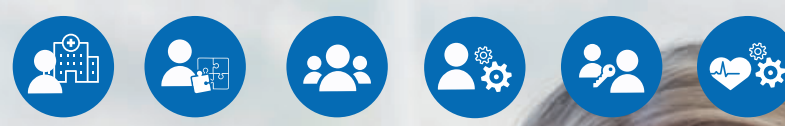

Expansion de notre présence en Suisse romande Notre bureau est situé à Lausanne

Depuis février 2018, nous sommes plus proches de vous et vous accueillons dans notre bureau de Lausanne:

\section{FMH Consulting Services AG}

Avenue d'Ouchy 66, 1006 Lausanne

tél. 0219224435 - Fax 0419250067

mail@fmhconsulting.ch - www.fmhservices.ch

FMH Services est à vos côtés pour toute question d’ordre économique, juridique et entrepreneurial.

\section{CONSEILS POUR MÉDECINS ET CABINETS}

\section{† FMHSERVICES}

Vous pouvez prendre contact avec nous sans aucune obligation par téléphone ou courrier électronique ou en nous retournant le talon-réponse par fax ou par la Poste. Nous vous contacterons.

Prénom / nom

Adresse

NPA / lieu

Téléphone privé / cabinet

Atteignable le plus facilement

CONSULTING

\section{FMH Consulting Services AG}

Avenue d'Ouchy 66, 1006 Lausanne

Tél. 0219224435 - Fax 0419250067

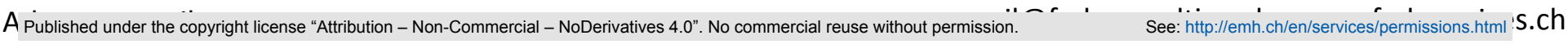

